\title{
Buenas prácticas en la declaración de obras huérfanas en Europa
}

\author{
Good practices in the declaration of orphan works in Europe
}

\author{
Rosario Arquero Avilés (1), Gonzalo MARco Cuenca (2), José Antonio Salvador Oliván (2) \\ (1) Departamento de Biblioteconomía y Documentación. Universidad Complutense de Madrid, España, \\ carquero@ucm.es (2) Departamento de Ciencias de la Documentación e Historia de la Ciencia, \\ Universidad de Zaragoza, España, gmarco@unizar.es, jaso@unizar.es
}

\begin{abstract}
Resumen
Se presenta un análisis de los proyectos europeos de preservación y digitalización del patrimonio cultural que, como ejemplo de buenas prácticas, han sido origen de la declaración de obras huérfanas. Para ello, se establece como fuente primaria para la identificación de los proyectos la información pública disponible en los registros de la Base de Datos de Obras Huérfanas del Observatorio de la Oficina de Propiedad Intelectual de la Unión Europea (EUIPO). En primer lugar, se analizan y se normalizan los datos de los 2.041 registros exportados de la citada base de datos. A continuación, se establecen diferentes rankings e indicadores. Por último, se presentan los 43 proyectos identificados, realizándose un análisis cualitativo y descriptivo de los proyectos basándose en la consulta de la información pública disponible online y en los contactos establecidos con algunos de sus responsables.
\end{abstract}

Palabras clave: Obras huérfanas. Declaración de obras huérfanas. Proyectos europeos. Digitalización. Base de datos de obras huérfanas. Patrimonio cultural y documental. Europa.

\section{Introducción}

En marzo de 2002, se elaboraron por encargo de la UNESCO y como resultado del trabajo de un grupo de expertos de la IFLA (International Federation of Library Associations) y de la ICA (International Council on Archives), las "Directrices para proyectos de digitalización de colecciones y fondos de dominio público, en particular para aquellos custodiados en bibliotecas y archivos" (1) (Ministerio de Cultura, 2002).

Estas directrices identifican y discuten las cuestiones clave relativas a la conceptualización, planificación e implementación de proyectos de digitalización de colecciones y fondos de dominio público, en particular para aquellas colecciones custodiadas en bibliotecas y archivos, incluyendo recomendaciones de "buenas prácticas" que deberían seguirse en las diferentes fases de los procesos de digitalización. En este mismo documento se recomienda que la primera cuestión a resolver en un proyecto o programa de

\begin{abstract}
This study presents an analysis of the European projects of preservation and digitisation of the cultural heritage that, as an example of good practices, have been the origin of the declaration of orphan works. For this purpose, the public information available in the records of the Orphan Works Database of the Observatory of the Intellectual Property Office of the European Union (EUIPO) is established as the primary source for the identification of projects. First, the data of the 2,041 records exported from the database are analysed and normalized. Next, different rankings and indicators are established. Finally, the 43 projects identified are presented and a qualitative and descriptive analysis is realized, based on the consultation of the public information available online and the contacts established with some of those responsible.
\end{abstract}

Keywords: Orphan works. Orphan works declaration. European projects. Digization. Orphan works database. European cultural heritage. Europe.

digitalización sean las condiciones legales para realizar copias digitales (Ministerio de Cultura, 2002).

En ese mismo contexto temporal, entre los años 2002 y 2004, surgen importantes iniciativas de digitalización masiva como la de Google Books (2), un servicio gratuito que implicaba, tal y como indica Esteve (2010):

[...] la digitalización de alrededor de quince millones de volúmenes, que Google calculaba llevar a cabo en unos diez años, para ponerlos a disposición del público mediante un servicio de búsqueda de libros ofrecido por la propia empresa bajo el nombre de Google Books Search (GBS).

Para ello, Google decidió acudir a la fuente depositaria de los libros, las bibliotecas, llegando a firmar acuerdos de digitalización con las principales bibliotecas universitarias norteamericanas, además de otras bibliotecas universitarias europeas de reconocido prestigio. En dicho contexto, se obvió a autores y editores, para acceder 
directamente a los contenidos a través de las colecciones de las bibliotecas. Tal y como indica Espín (2014):

Si bien la iniciativa de Google se centraba esencialmente en las obras literarias en dominio público, se acabó extendiendo a toda producción literaria de obras protegidas, incluidas obras huérfanas y/o fuera del comercio.

El proyecto, no ausente de controversia, se ha encontrado con diversos problemas técnicos y legales $\mathrm{y}$, entre estos últimos, destacan aquellos relacionados con la digitalización de obras huérfanas y los posibles intereses comerciales que puedan derivar de su uso. En este mismo sentido, y en relación a los proyectos de digitalización masiva de documentos, Espín (2014) expresa que:

[...] evidentemente ha sido Google quien ha marcado el ritmo del mercado y de las normas, en esta como en tantas otras materias. Por consiguiente, no se puede hacer un análisis del nuevo límite introducido por la declaración de obras huérfanas, si no se tiene en cuenta que la acción normativa comunitaria es la respuesta europea a Google.

En este escenario y con relación a la existencia de obras huérfanas, dentro de las colecciones europeas, se habla de un importante volumen. Para el Observatorio de la Oficina de Propiedad Intelectual de la Unión Europea (EUIPO, 2014) existen (3):

Millones de obras huérfanas en bibliotecas, museos y archivos de organismos de radiodifusión públicos y otras instituciones públicas de la Unión Europea; la British Library, por ejemplo, posee más de 150 millones de artículos y calcula que hasta el $40 \%$ de las obras creativas de sus colecciones podrían ser huérfanas.

En otro informe encargado por la Comisión Europea sobre la evaluación de la situación de las obras huérfanas (Vuopala, 2010) se indica la existencia de un alto número de obras huérfanas en Europa, con una estimación conservadora de 3 millones de libros, sujetos a derechos de autor que podrían ser obras huérfanas, lo que supone un $13 \%$ de los libros sujetos a derechos de autor en la Unión Europea.

La Directiva europea 2012/28/UE (4) sobre usos autorizados de obras huérfanas (Parlamento Europeo, 2012) viene a establecer un marco legal para facilitar la digitalización y divulgación de ciertas obras que se encuentran amparadas bajo los derechos de autor o derechos afines, no encontrándose en dominio público, y en las que se da la circunstancia de no haber sido posible identificar o localizar por ningún medio a los titulares de esos derechos o, dicho de otro modo, de obras huérfanas. En esta misma Directiva, en su artículo 3, apartado 6, se promueve la adopción por parte de los Estados miembros de las medidas necesarias para asegurar que la información sobre obras huérfanas quede registrada en una base de datos única, en línea y accesible al público, siendo creada y gestionada por la Oficina de Armonización del Mercado Interior (OAMI) que, a partir de marzo de 2016, pasó a denominarse Oficina de Propiedad Intelectual de la Unión Europea (EUIPO).

Con esta perspectiva se abrió, a finales del año 2014, la Base de datos de Obras Huérfanas de la EUIPO, un recurso que adquiere un papel significativo como repositorio central europeo de información sobre obras huérfanas, recopilando toda la información que sobre este tipo de materiales poseen las instituciones culturales europeas. La base de datos de Obras Huérfanas proporciona información detallada sobre la declaración de obras huérfanas contenidas en las colecciones de bibliotecas de acceso público, centros educativos, museos, archivos, instituciones dedicadas al patrimonio audiovisual y organismos públicos de radiodifusión establecidos en los Estados miembros.

Esta base de datos, de acuerdo con la Directiva europea 2012/28/UE, incluye información sobre una amplia variedad de tipologías documentales como, por ejemplo: obras impresas, como libros, diarios, periódicos, revistas y otros documentos impresos; obras cinematográficas o audiovisuales y fonogramas; obras inéditas bajo ciertas condiciones de licencia; obras insertadas o embebidas en otras obras impresas o en fonogramas, como por ejemplo ilustraciones, imágenes o fotografías; y obras parcialmente huérfanas, en concreto aquellas para las que se hayan identificado y localizado a uno o más titulares de los derechos y estos hayan autorizado el uso de la obra en relación con los derechos de los que son titulares.

Cabe señalar que en los últimos diez años, amparados por la legislación europea e iniciativas como la estrategia Europa 2020 (Comisión Europea, 2010a) y la Agenda Digital para Europa (Comisión Europea, 2010b), se han originado muchos proyectos relacionados con la preservación del patrimonio cultural europeo, tales como Europeana, donde se ha promovido la digitalización como un medio para la conservación y la difusión de aquellos materiales declarados de interés cultural, fomentando la creación de bibliotecas digitales que contribuyen al capital social y cultural europeo.

En este sentido, formando parte de las colecciones que han servido como base para el desarrollo de estos proyectos de digitalización, se han podido hallar y se siguen aún hallando una importante cantidad de obras huérfanas. Estos proyectos, por tanto, se constituyen como un pilar 
clave para la localización y posterior declaración de obras huérfanas, siendo una fuente de especial relevancia como origen de la declaración de obras huérfanas en la base de datos de la EUIPO.

\section{Objetivos y metodología}

En este estudio se propone como objetivo general la realización de un análisis y evaluación de los proyectos europeos que han originado la declaración de obras huérfanas a través del estudio de los registros públicos de la Base de datos de Obras Huérfanas de la EUIPO, lo que puede interpretarse como un ejemplo de buenas prácticas para el resto de países que aún no tienen ningún registro público de declaración de obras huérfanas en dicha base de datos.

Como objetivos específicos relacionados con este objetivo general, se formulan los siguientes: identificar los principales proyectos europeos relacionados con la declaración de obras huérfanas; identificar los países y organizaciones implicadas en estos proyectos; generar un ranking de proyectos a partir del número de registros principales de obras huérfanas declaradas; generar un ranking de proyectos atendiendo a sus tipologías documentales; y analizar y describir los proyectos más relevantes por número de registros principales declarados y tipologías documentales existentes.

Con respecto a la metodología, se ha seguido un método de investigación de tipo mixto en tres fases. En la primera fase, se han establecido, como datos de referencia, los registros públicos principales disponibles en la Base de datos de Obras Huérfanas de la EUIPO (en inglés, Orphan Works Database) (5). Estos datos se han obtenido a partir de una consulta general, por todos los campos, con fecha final de 15 de marzo de 2017. Los resultados obtenidos se exportaron para su análisis cuantitativo y estadístico a un analizador denominado APROH (6) basado en una hoja de cálculo. El contenido de este analizador incluye los siguientes campos: identificador $A P R O H$, número de archivo, título del trabajo, descripción, tipología, organización (entidad declarante), país, lengua de publicación y denominación del proyecto. Todos los datos han sido exportados de la base de datos de la EUIPO, a partir de su vista pública, excepto el identificador $\mathrm{APROH}$.

En la segunda fase, se seleccionaron los siguientes indicadores objeto de estudio: total de proyectos por países y número de registros declarados, total de proyectos por tipologías documentales $y$ número de registros declarados, porcentaje de registros atendiendo a su tipología documental, ranking de organizaciones por número de registros declarados, ranking de proyectos por número de registros y por tipología documental. Para poder llevar a cabo este análisis de tipo cuantitativo previamente se normalizan los valores de los campos: tipología, denominación del proyecto $y$, excepcionalmente, algunos nombres de organizaciones declarantes. A continuación, se analizan los indicadores y se establecen los rankings por medio de la generación de tablas dinámicas y consultas predefinidas en $\mathrm{APROH}$.

En la tercera fase, a partir del ranking de proyectos, atendiendo a su relevancia por número de registros declarados, más de20 registros, y su tipología documental, se realiza un análisis cualitativo y descriptivo basado en la consulta de la información pública disponible online sobre los proyectos y los contactos establecidos con algunos de sus responsables.

Este estudio se ha desarrollado durante el período comprendido entre el 15 de enero de 2017 y el 31 de marzo de 2017.

\section{Resultados}

Como resultado de la consulta pública de la Base de Datos de Obras Huérfanas de la EUIPO se obtuvieron un total de 2.041 registros principales, que contienen 7.704 obras integradas o embebidas. Estos registros están relacionados con un total de 14 países y 43 proyectos (ver figura 1 en la página siguiente). Hay que señalar que algunos de estos proyectos han dado origen a declaraciones de registros relacionados con más de una tipología documental.

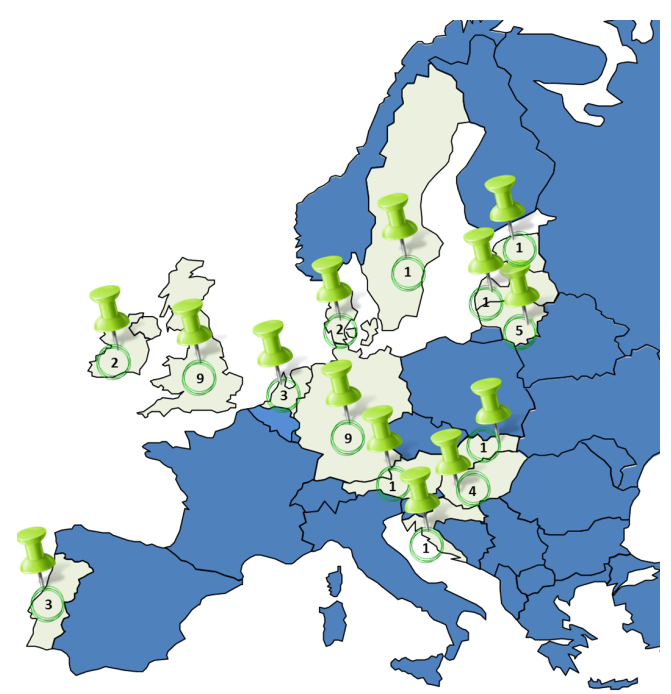

Figura 1. Países y número de proyectos que han dado origen a declaración de obras huérfanas

En cuanto a la evolución de los registros en la base de datos, a finales del año 2015 existían aproximadamente unos 1.430 registros (EUIPO, 
2016). Tal y como recoge el estudio de Arquero y Marco (2016), a mediados de noviembre de 2016, se habían declarado 1.979 registros y en el período comprendido entre el 15 de noviembre de 2016 y 15 de marzo de 2017 se han hecho públicos 62 nuevos registros. En la tabla I se puede observar la relación de países declarantes por orden alfabético, número de proyectos y número de registros asociados a esos proyectos. Entre los países con mayor número de proyectos destacan: Alemania y Reino Unido, seguidos de Lituania, Hungría y el resto con tres o menos proyectos. Sin embargo, cabe destacar que son los Países Bajos, con 3 proyectos y 801 registros, el país con mayor número de declaraciones de obras huérfanas.

A continuación, en la tabla II, podemos encontrar una relación de proyectos por países, organizaciones declarantes, denominación del proyecto, tipología y número total de registros declarados. Esta tabla se complementa con la tabla que aparece en el anexo I y que podemos encontrar al final del estudio. Dicha tabla anexa muestra una vista de todos los proyectos por orden alfabético y desde un enfoque temático, incluyendo una breve descripción de los mismos y otras informaciones de interés como: el nombre del proyecto, tipología documental, dirección web donde se ubica el proyecto y país de origen.

\begin{tabular}{lll}
\hline País & Número de proyectos & Registros \\
\hline Alemania & 9 & 80 \\
\hline Austria & 1 & 7 \\
\hline Croacia & 1 & 1 \\
\hline Dinamarca & 2 & 37 \\
\hline Eslovaquia & 1 & 4 \\
\hline Estonia & 1 & 25 \\
\hline Hungría & 4 & 525 \\
\hline Irlanda & 2 & 9 \\
\hline Letonia & 1 & 1 \\
\hline Lituania & 5 & 44 \\
\hline Países Bajos & 3 & 801 \\
\hline Portugal & 3 & 12 \\
\hline Reino Unido & 9 & 494 \\
\hline Suecia & 1 & 1 \\
\hline Total & 43 & 2.041 \\
\hline
\end{tabular}

Tabla I. Número de proyectos y registros por orden alfabético del país de origen

\begin{tabular}{|c|c|c|c|c|}
\hline País & Organización & Denominación del proyecto & Tipología & Reg. \\
\hline \multirow[t]{8}{*}{ Alemania } & Bauhaus-Archiv Berlin & $\begin{array}{l}\text { Bauhaus-Archiv e.V. } \\
\text { Museum für Gestaltung }\end{array}$ & $\begin{array}{l}\text { Obras } \\
\text { audiovisuales }\end{array}$ & 1 \\
\hline & $\begin{array}{l}\text { Deutsche Kinemathek - Museum } \\
\text { für Film und Fernsehen - } \\
\text { Deutsches Filminstitut }\end{array}$ & EFG 1914 & $\begin{array}{l}\text { Obras } \\
\text { audiovisuales }\end{array}$ & 5 \\
\hline & Deutsche Nationalbibliothek & d003 & Obras impresas & 3 \\
\hline & $\begin{array}{l}\text { Institut für Ost- und } \\
\text { Südosteuropaforschung } \\
\text { (Bibliothek) }\end{array}$ & $\begin{array}{l}\text { GeoPortOst } \\
\text { OstDok }\end{array}$ & $\begin{array}{l}\text { Obras impresas } \\
\text { Obras impresas }\end{array}$ & $\begin{array}{l}15 \\
14\end{array}$ \\
\hline & $\begin{array}{l}\text { Universität Hamburg } \\
\text { P. Walter Jacob-Archiv }\end{array}$ & $\begin{array}{l}\text { documentation on the fate of Jewish } \\
\text { inhabitants of the Thuringian town of } \\
\text { Altenburg (project by Christian Repkewitz) }\end{array}$ & Fotografía & 1 \\
\hline & $\begin{array}{l}\text { Stiftung Haus der Geschichte der } \\
\text { Bundesrepublik Deutschland }\end{array}$ & $\begin{array}{l}\text { background research } \\
\text { Suche in den Sammlungen } \\
\text { Sammlungen im Internet }\end{array}$ & $\begin{array}{l}\text { Obras } \\
\text { audiovisuales } \\
\text { Obras impresas } \\
\text { Obras impresas }\end{array}$ & \\
\hline & Technische Informationsbibliothek & TIB AV-Portal & $\begin{array}{l}\text { Obras } \\
\text { audiovisuales }\end{array}$ & 28 \\
\hline & $\begin{array}{l}\text { Universitätsbibliothek der } \\
\text { Humboldt-Universität zu Berlin }\end{array}$ & Digitalisierung & Obras impresas & 10 \\
\hline Austria & University of Innsbruck & diglib.uibk.ac.at & Obras impresas & 7 \\
\hline Croacia & $\begin{array}{l}\text { National and University Library in } \\
\text { Zagreb }\end{array}$ & Adrianskoga mora sirena & Obras impresas & 1 \\
\hline \multirow[t]{2}{*}{ Dinamarca } & Danish Film Institute & Online display & $\begin{array}{l}\text { Obras } \\
\text { audiovisuales }\end{array}$ & 36 \\
\hline & Statsbiblioteket & Europeana Sounds & Fonogramas & 1 \\
\hline Eslovaquia & Dominikánsky knižný inštitút & Digitalizácia fondu DKI & Obras impresas & 4 \\
\hline
\end{tabular}




\begin{tabular}{|c|c|c|c|c|}
\hline Estonia & National Library of Estonia & Digital National Imprint & $\begin{array}{l}\text { Obras impresas } \\
\text { Partituras }\end{array}$ & $\begin{array}{r}22 \\
3 \\
\end{array}$ \\
\hline \multirow[t]{2}{*}{ Hungría } & $\begin{array}{l}\text { Magyar Nemzeti Digitális } \\
\text { Archívum és Filmintézet } \\
\text { Hungarian National Digital } \\
\text { Archives and Film Institute }\end{array}$ & $\begin{array}{l}\text { gramofononline.hu } \\
\text { http://filmhiradokonline.hu/ } \\
\text { MaNDA Dokumentumfilmek }\end{array}$ & $\begin{array}{l}\text { Fonogramas } \\
\text { Obras } \\
\text { audiovisuales } \\
\text { Obras } \\
\text { audiovisuales }\end{array}$ & $\begin{array}{r}340 \\
1 \\
1\end{array}$ \\
\hline & $\begin{array}{l}\text { National Széchényi Library of } \\
\text { Hungary }\end{array}$ & ELDORADO & Obras impresas & 183 \\
\hline \multirow[t]{2}{*}{ Irlanda } & Fingal County Council Archives & Shackleton`s Mill Film Project & $\begin{array}{l}\text { Obras } \\
\text { audiovisuales }\end{array}$ & 1 \\
\hline & $\begin{array}{l}\text { Trinity College Dublin, the } \\
\text { University of Dublin }\end{array}$ & Clarke Stained Glass Studios Collection & Correspondencia & 8 \\
\hline Letonia & Natioanl Library of latvia & LNB GRĀMATU PORTĀLS & Obras impresas & 1 \\
\hline \multirow[t]{5}{*}{ Lituania } & Aušros" muziejus & LIMIS & Fotografía & 4 \\
\hline & $\begin{array}{l}\text { Gabrielè Petkevičaitè-Bitè } \\
\text { Panevėžys County Public Library } \\
\text { Kaunas county public library } \\
\text { Povilas Visinskis Siauliai County } \\
\text { Library }\end{array}$ & Virtual Electronic Heritage System & $\begin{array}{l}\text { Obras impresas } \\
\text { Obras impresas } \\
\text { Obras impresas }\end{array}$ & $\begin{array}{l}4 \\
1 \\
2\end{array}$ \\
\hline & $\begin{array}{l}\text { Martynas Mažvydas National } \\
\text { Library of Lithuania }\end{array}$ & $\begin{array}{l}\text { Presenting Works of the Lithuanian Classical } \\
\text { Literature Online }\end{array}$ & Obras impresas & 28 \\
\hline & $\begin{array}{l}\text { National M. K. Čiurlionis Museum } \\
\text { of Art }\end{array}$ & $\begin{array}{l}\text { Nenustatytų teisių turètojų kruopščios } \\
\text { paieškos vykdymas }\end{array}$ & Obras impresas & 3 \\
\hline & $\begin{array}{l}\text { Rokiškio rajono savivaldybès } \\
\text { Juozo Keliuočio viešoji biblioteka }\end{array}$ & Nr. TR-351 & Obras impresas & 2 \\
\hline \multirow[t]{2}{*}{$\begin{array}{l}\text { Países } \\
\text { Bajos }\end{array}$} & Eye Film Institute & $\begin{array}{l}\text { Film in Nederland } \\
\text { FORWARD }\end{array}$ & $\begin{array}{l}\text { Obras } \\
\text { audiovisuales } \\
\text { Obras } \\
\text { audiovisuales }\end{array}$ & $\begin{array}{l}133 \\
647\end{array}$ \\
\hline & Koninklijke Bibliotheek & DBNL & Obras impresas & 21 \\
\hline Portugal & Biblioteca Nacional de Portugal & $\begin{array}{l}\text { Diário da Guerra } \\
\text { Portal Macau/China (thematic website) } \\
\text { Portuguese National Digital Library }\end{array}$ & $\begin{array}{l}\text { Obras impresas } \\
\text { Partituras } \\
\text { Obras impresas } \\
\text { Partituras }\end{array}$ & $\begin{array}{l}6 \\
1 \\
4 \\
1\end{array}$ \\
\hline \multirow[t]{8}{*}{$\begin{array}{l}\text { Reino } \\
\text { Unido }\end{array}$} & $\begin{array}{l}\text { British Film Institute } \\
\text { Northern Ireland Screen }\end{array}$ & BFI Unlocking Film Heritage Britain on Film & $\begin{array}{l}\text { Obras } \\
\text { audiovisuales } \\
\text { Obras } \\
\text { audiovisuales }\end{array}$ & $\begin{array}{r}205 \\
3\end{array}$ \\
\hline & CREATe & $\begin{array}{l}\text { Digitising the Edwin Morgan Scrapbooks } \\
\text { Project }\end{array}$ & Obras impresas & 5 \\
\hline & $\begin{array}{l}\text { The National Archives. Humanist } \\
\text { Library and Archives }\end{array}$ & Architecture and Place & Obras impresas & 2 \\
\hline & IWM & IWM websites & $\begin{array}{l}\text { Obras } \\
\text { audiovisuales }\end{array}$ & 1 \\
\hline & King`s College, Cambridge & $\begin{array}{l}\text { Introduction to Archives: Rupert Brooke } \\
\text { website }\end{array}$ & Obras impresas & 7 \\
\hline & $\begin{array}{l}\text { Roman Roads Research } \\
\text { Association }\end{array}$ & Margary Online & Obras impresas & 1 \\
\hline & Stirling Council Archives & IAD2016 blog post & Planos & 3 \\
\hline & The British Library & $\begin{array}{l}\text { Europeana WW1 } \\
\text { Spare Rib Digitisation }\end{array}$ & $\begin{array}{l}\text { llustraciones } \\
\text { Obras impresas } \\
\text { Obras impresas }\end{array}$ & $\begin{array}{r}1 \\
39 \\
227\end{array}$ \\
\hline \multirow[t]{2}{*}{ Suecia } & Swedish National Heritage Board & Digitala Sveriges kyrkor & Obras impresas & 1 \\
\hline & & & Total & 2.041 \\
\hline
\end{tabular}

Tabla II. Relación de países, organizaciones, proyectos, tipologías y registros declarados 


\begin{tabular}{clcl}
\hline Top & Organización & $N^{\circ}$. & País \\
\hline 1 & Eye Film Institute & 780 & $\begin{array}{l}\text { Países } \\
\text { Bajos }\end{array}$ \\
\hline 2 & $\begin{array}{l}\text { Magyar Nemzeti Digitális } \\
\text { Archívum és Filmintézet }\end{array}$ & 342 & Hungría \\
\hline 3 & The British Library & 267 & $\begin{array}{l}\text { Reino } \\
\text { Unido }\end{array}$ \\
\hline 4 & British Film Institute & 205 & $\begin{array}{l}\text { Reino } \\
\text { Unido }\end{array}$ \\
\hline 5 & $\begin{array}{l}\text { National Széchényi Library of } \\
\text { Hungary }\end{array}$ & 183 & Hungría \\
\hline 6 & Danish Film Institute & 36 & Dinamarca \\
\hline 7 & $\begin{array}{l}\text { Institut für Ost- und } \\
\text { Südosteuropaforschung } \\
\text { (Bibliothek) }\end{array}$ & 29 & Alemania \\
\hline 8 & $\begin{array}{l}\text { Technische } \\
\text { Informationsbibliothek }\end{array}$ & 28 & Alemania \\
\hline 9 & $\begin{array}{l}\text { Martynas Mažvydas National } \\
\text { Library of Lithuania }\end{array}$ & 28 & Lituania \\
\hline 10 & National Library of Estonia & 25 & Estonia \\
\hline
\end{tabular}

Tabla III. Ranking top10 de organizaciones por número de registros declarados y país

Atendiendo a las organizaciones declarantes de obras huérfanas es el Eye Film Institute de los Países Bajos, con dos proyectos audiovisuales, quien lidera este ranking. En la tabla II podemos observar las diez primeras organizaciones por número de registros declarados.

En cuanto a las tipologías documentales de los registros declarados, son las obras audiovisuales, con 1.063 registros, las que ocupan el primer puesto; las obras impresas, con 615 registros, se encuentran en un segundo puesto; los fonogramas, con 341 registros en tercer lugar y el resto de tipologías documentales, con 22 registros, ocupan el último lugar.

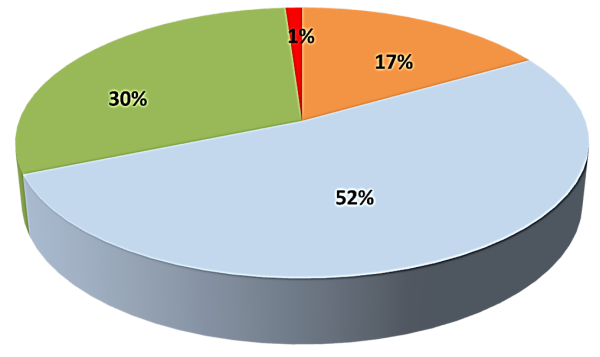

Monogramas Obras audiovisuales $m$ Obras impresas $\quad$ Otras tipologias

Figura 2. Porcentaje de registros atendiendo a su tipología documental

Con relación al número de proyectos por tipologías documentales son los proyectos relacionados con las obras impresas, con 24 proyectos, los que lideran este ranking, los proyectos audiovisuales se sitúan a continuación con 11 proyectos ocupando el segundo puesto, los proyectos relacionados con otras tipologías, partituras, correspondencia, fotografías, ilustraciones, planos, con 6 proyectos, ocupan el tercer puesto $\mathrm{y}$, por último, los fonogramas con 2 proyectos.

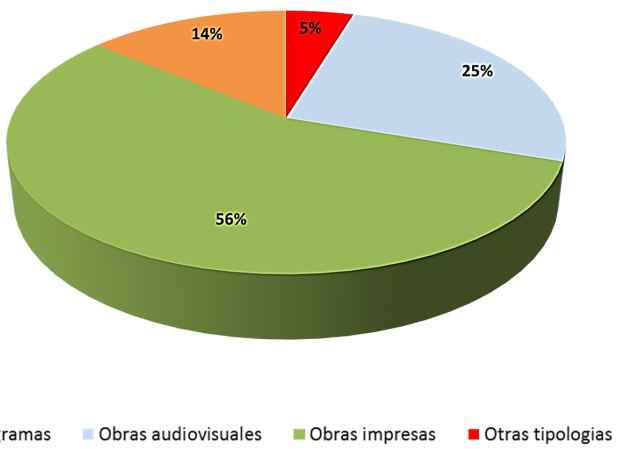

Figura 3. Porcentaje de proyectos atendiendo a su tipología documental.

\subsection{Proyectos de obras audiovisuales}

Dado que se trata de la tipología documental que mayor número de proyectos concentra, a continuación, se realiza una revisión de los proyectos que tienen más de 20 registros declarados de obras audiovisuales. En la tabla IV podemos observar el ranking de los proyectos audiovisuales por nombre y número de registros declarados.

\begin{tabular}{llr}
\hline Top & Proyectos audiovisuales & Registros \\
\hline 1 & FORWARD & 647 \\
\hline 2 & $\begin{array}{l}\text { BFI Unlocking Film Heritage } \\
\text { Britain on Film }\end{array}$ & 208 \\
\hline 3 & Film in Nederland & 133 \\
\hline 4 & Online display & 36 \\
\hline 5 & TIB AV-Portal & 28 \\
\hline 6 & EFG 1914 & 5 \\
\hline 7 & background research & 1 \\
\hline 8 & Bauhaus-Archiv e.V. Museum & 1 \\
\hline 9 & für Gestaltung & 1 \\
\hline 10 & http://filmhiradokonline.hu/ & 1 \\
\hline 11 & MaNDA Dokumentumfilmek & 1 \\
\hline 12 & Shackleton`s Mill Film Project & 1 \\
\hline & Total & 1.063 \\
\hline
\end{tabular}

Tabla IV. Ranking de proyectos de obras audiovisuales por número de registros 
3.1.1. FORWARD. Es con 647 registros principales declarados es el proyecto más importante de todos los analizados. El proyecto FORWARD, financiado por la Unión Europea (7), tiene como finalidad la creación de un sistema armonizado para evaluar y registrar la situación de los derechos de las obras audiovisuales europeas, sirviendo de apoyo para la identificación y registro de obras huérfanas. Este proyecto intenta facilitar un marco normalizado para la definición del estado de los derechos de las obras audiovisuales, que permita un acceso sistematizado y simplificado a gran parte de los activos culturales que están actualmente infrautilizados o son desconocidos en Europa (Comisión Europea, 2016). El proyecto es liderado por la Cinematheque Royale de Bélgica y fue programado inicialmente para una duración de tres años (2013-2016). En el mismo, participan 13 organizaciones de 10 países europeos, entre las que destacan 11 importantes filmotecas europeas. El proyecto ha sido también promovido desde sus inicios por la Asociación de Filmotecas y Archivos Cinematográficos Europeos (ACE) con la intención de facilitar la compensación de derechos de las películas a sus titulares $y$, en particular, para encontrar una solución para los cientos de miles de obras huérfanas preservadas en los archivos cinematográficos europeos (FORWARD, 2014). Como principales objetivos planteados en el contexto de este proyecto están:

- Crear un sistema paneuropeo que proporcione un marco para la evaluación del estado de los derechos de las obras audiovisuales (con derechos, dominio público, obra huérfana, obra parcialmente huérfana, etc.).

- Desarrollar un sistema de registro sistemático para las búsquedas diligentes (8) sobre el estado de los derechos.

- Crear un registro permanente de obras huérfanas audiovisuales.

- Coordinar el registro de obras huérfanas audiovisuales, desarrollando funcionalidades, para exportar los resultados de los registros y búsquedas realizadas a la base de datos europea de obras huérfanas gestionada por la EUIPO.

- Ayudar a las instituciones europeas de patrimonio cinematográfico y audiovisual en la aplicación de la Directiva europea relativa a las obras huérfanas.

- Mejorar la interoperabilidad entre el registro de FORWARD y los datos de las filmotecas participantes, mediante el uso de identificadores, incrementando su utilidad gracias a los datos enlazados.
En cuanto a resultados, se han implementado 11 marcos legales europeos diferentes en el sistema y se ha monitorizado la implementación de la Directiva europea de obras huérfanas en 11 países miembros. También se han importado 492.883 registros de obras y autoridades de los catálogos de las organizaciones participantes y han sido integrados en el registro de FORWARD. Del mismo modo, se ha integrado y comprobado la coincidencia de 26.465.213 registros de VIAF (Virtual International Authority File) y el catálogo FOR$W A R D$. Además, se han analizado y recopilado 232 fuentes externas para el procedimiento de búsqueda diligente (bases de datos, catálogos nacionales, entidades de gestión, asociaciones profesionales, etc.) (FORWARD, 2014)

3.1.2. BFI Unlocking Film Heritage Britain on Film. Este proyecto del British Film Institute (BFI) de Desbloqueo del Patrimonio Británico Cinematográfico (en inglés, Unlocking Film Heritage Britain on Film) es uno de los compromisos de digitalización de fondos adquirido por el BFI para garantizar la conservación, preservación y el acceso público al material histórico cinematográfico del Reino Unido. El proyecto comienza con la digitalización de los recursos cinematográficos, pero forma parte de un programa mucho más amplio de preservación y digitalización que pretende desbloquear y, por tanto, hacer accesibles más de 10.000 títulos seleccionados del archivo del $\mathrm{BFI}$, de archivos regionales y nacionales y de titulares de derechos de todo el Reino Unido (British Film Institute, a). El proyecto cuenta con una aportación gubernamental de 5 millones de libras esterlinas para apoyar la digitalización de 5.000 títulos de materiales audiovisuales de importantes colecciones públicas y particulares de todo el Reino Unido (British Film Institute, b). Por medio de este proyecto se desea asegurar que los ciudadanos británicos, profesionales del cine, educadores, investigadores y otros posibles usuarios de todo el mundo puedan acceder y disfrutar de estas obras del cine británico.

3.1.4. Online display. El proyecto de exhibición en línea del Instituto danés del Cine es un proyecto de digitalización de obras audiovisuales que tiene como objetivo conservar y hacer accesible abiertamente el patrimonio audiovisual nacional. El proyecto es el resultado de la cooperación entre diversas instituciones culturales danesas relacionadas con el cine, la radiotelevisión y otras entidades del sector audiovisual.

3.1.5. TIB AV-Portal. Es una plataforma web para la difusión de videos científicos y educativos con calidad evidenciada de disciplinas como: ingeniería, arquitectura, tecnologías de la información, matemáticas, física, química, medicina, historia, psicología, ciencias de la información, etc. El 
proyecto nace en julio de 2011 por medio de la colaboración entre el Centro de Competencia para Materiales no textuales de la Biblioteca Nacional de Ciencia y Tecnología de Alemania (TIB) en cooperación con el Instituto Hasso Plattner de Ingeniería de Sistemas de Software de la Universidad de Potsdam en Alemania. El portal TIB AV, resultado tangible del proyecto, se puso en línea en la primavera de 2014 y actualmente incluye más de 8.600 videos (TIB AV-Portal). Los videos pueden descargarse en diferentes formatos, así como los materiales relacionados que los acompañan: documentos pdf, presentaciones, etc. La gran mayoría de los videos se encuentran en idioma inglés o no incluyen contenido lingüístico, centrándose estos últimos en demostraciones científicas o presentaciones técnicas.

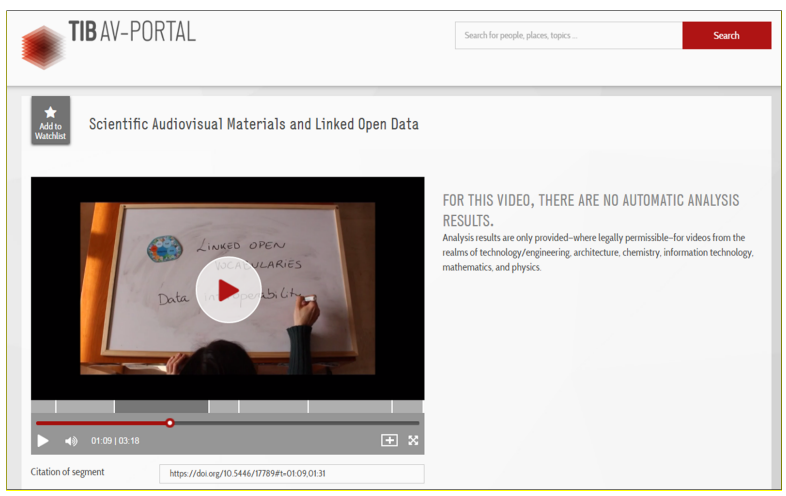

Figura 4. Captura de uno de los registros de videos científicos y educativos de TIB-AV Portal

\subsection{Obras impresas}

Con relación a los proyectos de obras impresas con más de 20 registros declarados en la base de datos de obras huérfanas se encuentran: Spare Rib (de la Bristish Library) con 227 registros, ELDORADO (de la National Széchényi Library de Hungría) con 183 registros, Europeana WW1 con 39 registros (declarados por la British Library), Presenting Works of the Lithuanian Classical Literature Online (de la Martynas Mažvydas National Library of Lithuania) con 28 registros, Digital National Imprint (de la National Library of Estonia) con 22 registros y, por último, DBNL (de la Koninklijke Bibliotheek de Países Bajos) con 21 registros.

En la presente revisión de los proyectos también se incluye una mención al proyecto Digitising the Edwin Morgan Scrapbooks Project al ser el primer proyecto de digitalización en el Reino Unido que aborda los problemas de derechos de las obras y se centra en la identificación de obras huérfanas.

\begin{tabular}{|c|c|c|}
\hline Top & Proyectos de obras impresas & $N^{\circ}$ \\
\hline 1 & Spare Rib Digitisation & 227 \\
\hline 2 & ELDORADO & 183 \\
\hline 3 & Europeana WW1 & 39 \\
\hline 4 & $\begin{array}{l}\text { Presenting Works of the Lithuanian } \\
\text { Classical Literature Online }\end{array}$ & 28 \\
\hline 5 & Digital National Imprint & 22 \\
\hline 6 & DBNL & 21 \\
\hline 7 & GeoPortOst & 15 \\
\hline 8 & OstDok & 14 \\
\hline 9 & Digitalisierung & 10 \\
\hline 10 & diglib.uibk.ac.at & 7 \\
\hline 11 & $\begin{array}{l}\text { Introduction to Archives: Rupert Brooke } \\
\text { website }\end{array}$ & 7 \\
\hline 12 & Virtual Electronic Heritage System & 7 \\
\hline 13 & Diário da Guerra & 6 \\
\hline 14 & $\begin{array}{l}\text { Digitising the Edwin Morgan Scrapbooks } \\
\text { Project }\end{array}$ & 5 \\
\hline 15 & Digitalizácia fondu DKI & 4 \\
\hline 16 & Portal Macau/China (thematic website) & 4 \\
\hline 17 & d003 & 3 \\
\hline 18 & $\begin{array}{l}\text { Nenustatytų teisių turètojų kruopščios } \\
\text { paieškos vykdymas }\end{array}$ & 3 \\
\hline 19 & Architecture and Place & 2 \\
\hline 20 & $\begin{array}{l}\text { Kruopšti paieška atlikta pagal sutarti Nr. } \\
\text { TR-351 }\end{array}$ & 2 \\
\hline 21 & Adrianskoga mora sirena & 1 \\
\hline 22 & Digitala Sveriges kyrkor & 1 \\
\hline 23 & $\begin{array}{l}\text { LNB Gramatu Portals } \\
\text { (http://gramatas.Indb.Iv/) }\end{array}$ & 1 \\
\hline 24 & Margary Online & 1 \\
\hline 25 & Sammlungen im Internet & 1 \\
\hline \multirow[t]{2}{*}{26} & Suche in den Sammlungen & 1 \\
\hline & Total & 615 \\
\hline
\end{tabular}

Tabla V. Ranking de proyectos de obras impresas por número de registros

3.2.1. Spare Rib. El proyecto de la British Library "Spare Rib Digitisation" ocupa el primer puesto en el ranking de proyectos de obras impresas por número de registros declarados en la base de datos de obras huérfanas (OWD). Este proyecto es un claro ejemplo de la gran cantidad de obras huérfanas que podemos encontrarnos en algunos tipos de materiales como, por ejemplo, en las publicaciones periódicas, que contienen textos, imágenes y/o ilustraciones en los que, en muchos casos, se desconoce su autoría. Spare Rib fue la revista más importante del Movimiento de Liberación de la Mujer en Gran Bretaña entre los años setenta y ochenta. La trayectoria de Spare 
Rib refleja el desarrollo del Movimiento de Liberación de la Mujer, resultando de especial interés para historiadores, académicos, activistas feministas y para aquellos que estudian los movimientos sociales y la historia de los medios de comunicación. La revista presenta una gran miscelánea de temas, entre los que se incluyen: sexualidad y salud, cuidado del hogar y de los niños, educación y trabajo, arte y cultura, representación e identidad y derechos legales de la mujer (British Library).

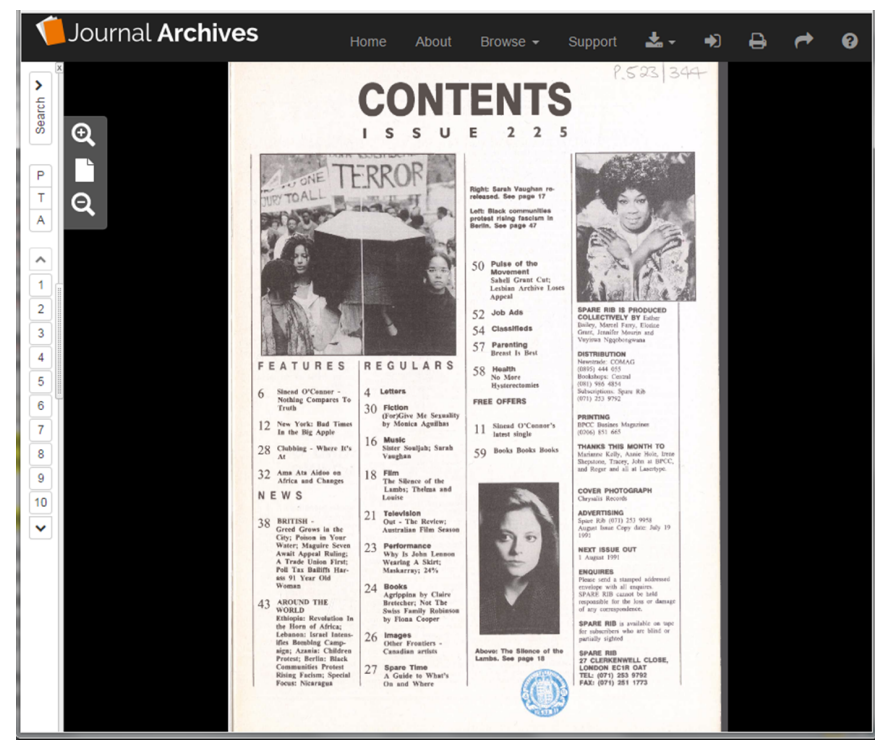

Figura 5. Captura del archivo digital de la revista en la plataforma Jisc

El proyecto Spare Rib se ha basado en la digitalización de la colección completa de la revista, incluyendo todos sus números, con una cobertura que va desde el año 1972 hasta el año 1992. El proyecto presenta como resultados dos recursos web: la página web Spare Rib, https://www.bl.uk/spare-rib, contiene 24 artículos sobre el contexto e historia de la revista y 300 ejemplos con contenidos seleccionados; y el archivo digital de la revista, que se encuentra disponible de forma gratuita a través de la plataforma de archivos de revistas Jisc (9) y que incluye aproximadamente el $20 \%$ del contenido de la revista a baja resolución, correspondiéndose con las contribuciones de aproximadamente 1.000 personas $(10)$.

3.2.2. ELDORADO. Sus siglas se corresponden con el Sistema Nacional, Base de datos y Biblioteca de documentos electrónicos (11) de la Biblioteca Nacional Széchényi, el proyecto de digitalización y preservación de materiales culturales más importante de Hungría. La Biblioteca Nacional húngara lidera este proyecto actuando como cliente y la empresa proveedora de servicios
Monguz Ltd. es la encargada de la digitalización. En el proyecto también participan y colaboran activamente otras bibliotecas húngaras y otros miembros interesados como editoriales, libreros, agencias gubernamentales, responsables de la protección de los derechos de autor, etc. El sistema ELDORADO tiene como objetivo principal la digitalización de todo tipo de documentos para proporcionar acceso al contenido de muchos de los materiales que se encuentran disponibles en las estanterías de las bibliotecas húngaras o fuera del circuito comercial. Tal y como se indica en el mismo proyecto, se busca la "reanimación" de estas obras, proporcionando contenidos electrónicos de manera legítima para que atiendan a los desafíos de una sociedad digital (National Széchényi Library, 2015).

El sistema ELDORADO es complejo, ya que pretende la inclusión de una gran diversidad de materiales, protegidos por derechos de autor o no (obras huérfanas, descatalogadas, en dominio público, etc.). Además, no solamente atiende a obras literarias, el proyecto incluye otras tipologías documentales como fotografías, audiovisuales, ilustraciones, etc. ELDORADO funciona proporcionando copias digitales de documentos bajo demanda. La solicitud de copias digitales de estas publicaciones, que son prácticamente imposibles de comprar, puede realizarse por particulares u organizaciones empresariales. Los servicios de valor añadido del sistema van desde la posibilidad de búsqueda de materiales (dentro del catálogo y con muchos registros disponibles a texto completo) hasta el préstamo electrónico. ELDORADO es un servicio conjunto de la comunidad bibliotecaria húngara que proporciona una infraestructura común para todas las bibliotecas asociadas al proyecto y sirve de apoyo y sistema de estandarización de los procesos de digitalización y de suministro de copias digitales, incluyendo el proceso de legitimación de derechos de autor. La mayoría de los usuarios de ELDORADO suelen ser las bibliotecas asociadas que requieren la infraestructura para la digitalización de obras de interés cultural $y$, además, demandan ayuda técnica legal para la "liberación" del contenido protegido por derechos de autor para, de este modo, poder proporcionar el material a un amplio círculo de usuarios (National Széchényi Library, 2015).

\subsubsection{Europeana WW1. El proyecto Europeana 1914-1918 - historias no contadas e historias ofi- ciales de la Primera Guerra Mundial (bajo las si- glas, Europeana WW1) es un proyecto de inter- cambio de recursos y digitalización de materiales sobre la Primera Guerra Mundial. El proyecto mezcla los recursos procedentes de bibliotecas y archivos audiovisuales de diferentes países con}


recuerdos e historias personales y familiares aportadas por usuarios (Europeana 1914-1918). De este modo, el proyecto aglutina diferentes contenidos y materiales con una perspectiva histórica única, donde se pueden contemplar materiales de las colecciones nacionales de importantes bibliotecas y filmotecas, conjuntamente con las contribuciones personales de los usuarios a través de la recopilación de cartas, fotografías y otros recuerdos de la guerra. Europeana WW1 es, principalmente, el resultado de la fusión de tres proyectos europeos con el objetivo de crear una perspectiva única. Estos proyectos son: The Europeana Collections 1914-1918, que pone en relieve los materiales de este periodo histórico con origen en las colecciones nacionales de bibliotecas, produciendo una colección digital de más de 400.000 piezas, el proyecto European Film Gateway 1914, con la participación de las principales filmotecas europeas, que aporta 650 horas de películas y material relacionado con la contienda bélica y, por último, Historias del público - Europeana 1914-1918, en colaboración con la Universidad de Oxford y otros socios europeos, que recopila materiales para ser digitalizados y compartidos en línea de procedencia particular, donde a finales del 2013 ya se habían digitalizado más de 60.000 artículos (Europeana 1914-1918).

3.2.4. Presenting Works of the Lithuanian Classical Literature Online. Proyecto de digitalización de obras de la literatura clásica lituana desarrollado por la Biblioteca Nacional Martynas Mazvydas de Lituania (ePaveldas). El proyecto se encuentra alineado con los objetivos nacionales de emprendimiento, fomento de la digitalización y conservación del patrimonio cultural lituano para garantizar el acceso al público por diversos medios, tecnologías y servicios electrónicos. Este proyecto tiene como objetivo la creación de una biblioteca de libros electrónicos con aproximadamente 600 obras digitalizadas de autores de la literatura clásica lituana y la aplicación de medios modernos para el acceso público a los libros en diversos formatos: pdf, ePub, html, txt o mobipocket.

3.2.5. Digital National Imprint. El proyecto de archivo digital de la Biblioteca Nacional de Estonia, DIGAR, recopila tipologías documentales como libros, periódicos, revistas, mapas, partituras, fotografías, postales y, recientemente, se han añadido grabaciones sonoras. Los documentos se encuentran accesibles al público y se pueden recuperar mediante un sistema que facilita la búsqueda por diversos campos como autor, título o palabras clave. El proyecto contiene 2.742 registros de objetos digitalizados e incluye también la digitalización de otros materiales manuscritos de alto interés cultural para la región como, por ejemplo, la Crónica de Enrique de Livonia, una de las fuentes más importantes del siglo XIII para Estonia y Letonia. También cuenta con una extensa colección de materiales digitalizados que proceden de 525 periódicos (publicados entre 1821-1944). Desde el año 2014, también se puede acceder a todos los contenidos de periódicos y, desde el año 2017, se han incluido 7 revistas y 1 publicación seriada. Esta colección contiene 164.876 registros que incluyen 1.704 .529 páginas y 4.721 .875 artículos. Todo este material se puede recuperar a través de una base de datos denominada DEA (National Library of Estonia, 2017). La base de datos se actualiza a diario. El proyecto presenta como principal resultado un portal web unificado, tanto para objetos digitalizados, como para artículos de todos los periódicos estonios, revistas y otras publicaciones creadas en su origen digitalmente o que hayan sido digitalizadas, publicadas a nivel nacional o en el extranjero en lengua estonia.

3.2.6. DBNL. La Biblioteca Digital de Literatura Holandesa (en holandés, Digitale Bibliotheek voor de Nederlandse Letteren (DBNL)), es una colección digital de textos pertenecientes a la literatura holandesa, la lingüística y la historia cultural de los Países Bajos desde su nacimiento hasta la actualidad. El proyecto surge de la colaboración de tres instituciones holandesas: la Taalunie, la Biblioteca de Herencia flamenca (Vlaamse Erfgoedbibliotheek) y la Biblioteca Real de La Haya (Koninklijke Bibliotheek te Den Haag). Desde su lanzamiento en 1999, el proyecto ha ido acumulando miles de textos literarios, además de información adicional como biografías y material audiovisual. La página web de la DBNL tiene anualmente más de cuatro millones de accesos (DBNL). El proyecto admite las solicitudes de digitalización de los propios usuarios, siempre que se ajusten al perfil del proyecto: literatura, lingüística e historia cultural holandesa.

3.2.7. Digitising the Edwin Morgan Scrapbooks Project. Proyecto de digitalización de los álbumes de recortes del poeta y traductor escocés Edwin Morgan. En el proyecto participan de forma colaborativa la Biblioteca de la Universidad de Glasgow y la Universidad de Queen's de Belfast, con el apoyo de la Fundación Edwin Morgan y CREATe (Centro de Investigación de Derechos de Autor, Nuevos Modelos de Negocios e Iniciativa Creativa). Este proyecto presenta el primer estudio en el Reino Unido que aborda las realidades legales y prácticas de la búsqueda diligente desde la entrada en vigor de la Directiva europea y el Orphan Works Licencing Scheme (OWLS) (Digitising the Edwin Morgan Scrapbooks, 2017). Esta colección contiene material huérfano 
relacionado con recortes de periódicos, revistas y libros. El proyecto incluye, además, un conjunto de recursos que proporcionan una guía práctica sobre cuestiones relevantes para instituciones que participen en iniciativas similares de digitalización.

\subsection{Fonogramas}

El proyecto de digitalización más importante relacionado con fonogramas es Gramofon Online. Este proyecto húngaro cuenta con 340 registros en la base de datos de obras huérfanas. Gramofon Online es un proyecto para la preservación y digitalización del patrimonio cultural sonoro húngaro, donde se recopilan y procesan grabaciones en discos de gramófono de $78 \mathrm{rpm}$ producidos y emitidos en Hungría desde 1.906, fecha de producción de las primeras grabaciones fonográficas en ese país (Gramofon Online, 2017).

\begin{tabular}{lll}
\hline Top & Proyectos de fonogramas & $N^{\circ}$ \\
\hline 1 & gramofononline.hu & 340 \\
\hline 2 & Europeana Sounds & 1 \\
\hline & Total & 341
\end{tabular}

Tabla V. Ranking de proyectos de fonogramas por número de registros

Gramofon Online se centra en recopilar y digitalizar fonogramas para ponerlos a disposición pública a través de Internet. La página web oficial del proyecto fue inaugurada en abril de 2010 con una base de datos inicial con cerca de 2000 registros. De este modo, el proyecto busca facilitar la conservación y difusión de estas obras, que se encuentran en un formato obsoleto, para que puedan ser escuchadas sin restricciones y de forma gratuita y, en cierto modo, para que puedan ser devueltas a la vida y no caigan en el olvido, ya que en muchos casos son obras patrimoniales totalmente desconocidas. La base de datos incluye más de 50 catálogos en línea, organizados por intérpretes, autores, géneros, años, fabricantes, etc. Todas las grabaciones pueden ser reproducidas y escuchadas, pero no está permitida la descarga de contenidos.

El proyecto se ha basado en un modelo colaborativo con la intención de construir una colección "desde abajo hacia arriba", donde los coleccionistas privados pueden hacer públicas sus grabaciones y compartir sus conocimientos con otros coleccionistas y el público en general (Gramofon Online, 2017). Además, el público puede realizar valoraciones de los registros sonoros incluidos en el proyecto, promoviendo la base de datos de conocimientos relacionados con este importante activo cultural húngaro.

Las redes sociales juegan también un papel importante en el proyecto para el intercambio de experiencias relacionadas con estos registros, disponiendo todos los registros de un botón para compartir grabaciones sonoras con enlaces para las principales redes sociales del país: Facebook, IWiW o Twitter, así como páginas en estas redes relacionadas con el proyecto.

El proyecto esta administrado por Neumann Nonprofit Kft una organización sin ánimo de lucro fundada en 1997 para el desarrollo de proyectos de digitalización en el sector de la cultura. Actualmente, el proyecto se encuentra integrado en los fondos del MaNDA (Archivo Nacional Digital de Hungría e Instituto de Cine Digital) (12).

\subsection{Otros proyectos}

Con relación a otros proyectos se presenta en la tabla VI el ranking de los mismos atendiendo al nombre del proyecto, números de registros declarados y tipología documental. El más destacado, con 8 registros, es el proyecto de digitalización de los archivos de la compañía Joshua Clarke \& Sons y su sucesor, Harry Clarke Stained Glass Limited, desarrollado por el Departamento de Recursos Digitales e Imagen de los Servicios de la Trinity College Library en Dublín. La colección consta de más de 1.400 diseños para vidrieras, así como otros documentos de esta firma, incluyendo la correspondencia con clientes, presupuestos, libros de pedidos y contabilidad y otros expedientes.

\begin{tabular}{clcl}
\hline Top & Otros proyectos & $N^{\circ}$ & Tipología \\
\hline 1 & $\begin{array}{l}\text { Clarke Stained Glass } \\
\text { Studios Collection }\end{array}$ & 8 & Correspondencia \\
\hline 2 & LIMIS & 4 & Fotografías \\
\hline 3 & Digital National Imprint & 3 & Partituras \\
\hline 4 & IAD2016 blog post & 3 & Partituras \\
\hline 5 & $\begin{array}{l}\text { documentation on the } \\
\text { fate of Jewish } \\
\text { inhabitants of the } \\
\text { Thuringian town of }\end{array}$ & 1 & Fotografias \\
& Altenburg & 1 & Ilustraciones \\
\hline 6 & Europeana WW1 & 1 & Partituras \\
\hline 7 & Diário da Guerra & 1 & Partituras \\
\hline 8 & $\begin{array}{l}\text { Portuguese National } \\
\text { Digital Library }\end{array}$ & 22 & \\
\hline & Total &
\end{tabular}

Tabla VI. Ranking de otros proyectos por número de registros y tipologías documentales 


\section{Conclusiones}

La digitalización de una obra supone fundamentalmente la transformación de la misma de un formato impreso o analógico a un formato digital, lo que suele llevar aparejado un proceso de reproducción y de puesta a disposición pública de la misma que puede afectar directamente a los derechos de autor.

El caso de las obras huérfanas, ampliamente recurrente cuando se desarrollan proyectos de digitalización masiva, conlleva la localización de obras cuyos titulares de derechos no están identificados, o de estarlo, no están localizados a pesar de haberse efectuado una búsqueda diligente previa de los mismos.

Este es el caso de los 43 proyectos estudiados como ejemplo de buenas prácticas de declaraciones en la base de datos de obras huérfanas de la EUIPO. En la mayoría de los casos, el objetivo de estos proyectos es la preservación y difusión del patrimonio documental europeo, buscando rescatar del olvido muchas obras que, de otro modo, no podrían ser descubiertas por el público en general.

Son destacables los proyectos audiovisuales, como por ejemplo FORWARD, donde se ha podido descubrir, y aún se espera explotar, un auténtico "filón" en cuanto a materiales huérfanos se refiere. La existencia de un gran número de proyectos relacionados con la digitalización de obras impresas pone también en evidencia esta realidad: la presencia de obras huérfanas, ya se trate de documentos originales (libros, revistas, carteles, correspondencia, etc.) o de una parte integrada en ellos (como es el caso de las fotografías, ilustraciones, mapas, etc.) que se configuran como un importante hallazgo, pero también como un problema o un desafío para el desarrollo de algunos proyectos.

La digitalización presenta, por tanto, una serie de características claves fundamentales y que tienen que ver con aspectos culturales, sociales, económicos, técnicos y, evidentemente, legales. Las instituciones que se ven inmersas en este tipo de proyectos, si no tienen todas las garantías en la identificación de los titulares de los derechos, evitarán o pospondrán, en muchos casos, la digitalización de esas obras y, por consiguiente, la sociedad europea quedará privada de un acervo documental de importante valor.

Como consecuencia, es necesario generar sistemas de ayuda que agilicen la generación de expedientes de búsquedas diligentes, de modo que las instituciones europeas que tienen que tomar decisiones sobre la digitalización del patrimonio documental (incluidas las potenciales obras huérfanas), no se vean condicionadas por los inconvenientes relacionados con la identificación de los titulares de los derechos, que pueden tener asociados costes muy altos en tiempo y recursos. Estos sistemas resultarían muy útiles tanto para los países que aún no han declarado obras huérfanas (la mitad de los países de la Unión Europea) como para las autoridades nacionales competentes de cada país que deben dar por buenos los registros de declaración de estas obras de los respectivos países.

\section{Agradecimientos}

Este artículo es un resultado de investigación en el marco del Proyecto I+D+i. Digitalización del Patrimonio Documental en España. Prospección y propuesta metodológica para facilitar el acceso y uso de obras huérfanas. Referencia: CSO201564292-R (MINECO/FEDER, UE).

\section{Notas}

(1) Estas directrices se enmarcan en la estrategia de la UNESCO de conocimiento para todos, que mantienen una estrecha relación con el Programa "Memoria del Mundo" de la UNESCO cuyo objetivo es la salvaguarda del patrimonio documental internacional, el acceso democrático a dicho patrimonio, el conocimiento creciente de su significado y la necesidad de preservarlo (Ministerio de Cultura, 2002).

(2) Conocido en sus inicios como Google Print y después como Google Books Search (GBS).

(3) Esta información, difundida por la EUIPO, procede del estudio realizado por la British Library sobre digitalización entre los años 1870-2010 en el que se establece entre sus conclusiones una estimación del $43 \%$ de obras huérfanas (Stratton, 2011).

(4) Esta directiva tiene su transposición en nuestro país en el Real Decreto 224/2016, por el que se desarrolla el régimen jurídico de las obras huérfanas a nivel nacional (España, 2016).

(5) Esta base se encuentra disponible en: https://euipo.europa.eu/orphanworks/

(6) Analizador de Proyectos Relacionados con Obras Huérfanas (APROH), elaborado por los autores de este estudio para el análisis cuantitativo y estadístico de los datos.

(7) El presupuesto de FORWARD para el período de 1-072013 hasta el 30-06-2016 ha sido de 5.035.250 euros, de los que 2.517.623 euros han sido una contribución de la Unión Europea (Comisión Europea, 2016).

(8) La búsqueda diligente es una pieza clave para la identificación de los derechos de las obras y la generación de expedientes relacionados con las obras huérfanas, convirtiéndose en un mecanismo imprescindible para garantizar mediante evidencias que se han puesto todos los medios necesarios para identificar y localizar a los titulares de los derechos. Según, el artículo 4 del Real Decreto $224 / 2016$, una búsqueda diligente es un procedimiento que tiene por objeto la identificación y localización del titular o titulares de los derechos de autor de una obra huérfana. Dicho procedimiento, de obligado cumplimiento previo uso de la obra, debe ser llevado a cabo de buena fe por las entidades beneficiarias (España, 2016).

(9) Este archivo digital se encuentra disponible en: https://journalarchives.jisc.ac.uk/britishlibrary/sparerib 
(10) Algunos materiales de la plataforma de archivo de revistas de Spare Rib han sido borrados provisionalmente hasta que la British Library pueda asegurar los permisos de copyright. Por este motivo y con el objetivo de ofrecer la versión más completa de la revista, desde la página web de la revista se hace un llamamiento para la búsqueda de posibles autores o colaboradores de contenidos no identificados (British Library).

(11) En húngaro, ELektronikus Dokumentumküldés Országos Rendszere, Adatbázisa y DOkumentumtára (ELDORADO).

(12) En húngaro, Magyar Nemzeti Digitális Archivum és Filmintézet. Para más información se puede consultar: http://mandarchiv.hu/

En la edición digital de la revista está disponible un apéndice con la relación de proyectos estudiados.

\section{Referencias}

Arquero Avilés, Rosario; Marco Cuenca, Gonzalo (2016). Análisis del estado de declaración de obras huérfanas en Europa. // Revista General de Información y Documentación. 26:2, 365-385.

British Film Institute (BFI) (a). Unlocking Film Heritage. Unlocking Film Heritage is a central priority of the BFI Film Forever strategic plan. http://www.bfi.org.uk /britain-on-film/unlocking-film-heritage

British Film Institute (BFI) (b). Digitisation Fund. BFI's Unlocking Film Heritage Digitisation Fund./I http://www.bfi.org.uk/supporting-uk-film/funding-organisations/unlocking-film-heritage-digitisation-fund

British Library. About the Spare Rib Digitisation Project. https://www.bl.uk/spare-rib/about-the-project

Comisión Europea (2010a). Europa 2020: una estrategia para un crecimiento inteligente, sostenible e integrador. COM (2010) 2020 final. http://eur-lex.europa.eu/legal-content/ ES/TXT/PDF/?uri=CELEX:52010DC2020\&from=ES

Comisión Europea (2010b). Comunicación de la Comisión al Parlamento Europeo, al Consejo, al Comité Económico y Social Europeo y al Comité de las Regiones: una agenda digital para Europa. http://eur-lex.europa.eu/legal-content/ES/TXT/PDF/?uri=CELEX: $52010 D C 0245 R(01) \&$ from $=E N$

Comisión Europea (2016). CORDIS. Community Research and Development Information Service. FORWARD. http://cordis.europa.eu/project/rcn/191763_en.html

DBNL. Digitale Bibliotheek voor de Nederlandse Letteren (DBNL). Over DBNL. http://www.dbnl.org/overdbnl/index.php

Digitising the Edwin Morgan Scrapbooks (2017). About the Project. /http://www.digitisingmorgan.org/About

ePaveldas. Presenting Works of the Lithuanian Classical Literature Online. http://www.epaveldas.It/en/e_klasikosprojektas

España (2016). Real Decreto 224/2016, de 27 de mayo, por el que se desarrolla el régimen jurídico de las obras huérfanas. // Boletín Oficial del Estado. 11 de Junio de 2016. 141; 39229-39236.

Espín Alba, Isabel (2014). Obras huérfanas y derecho de autor. Cizur Menor (Navarra): Aranzadi, 2014.

Esteve, Asunción (2010). Análisis legal del Proyecto Google Books desde la perspectiva de los derechos de propiedad intelectual. // Bid. Textos universitaris de biblioteconomia i documentació. 24 (Junio 2010). http://bid.ub.edu/24/esteve2.htm.

EUIPO (2014). Noticias: ya está disponible la base de datos de obras huérfanas. https://euipo.europa.eu/ohimportal/es/news/action/-/view/1595189

EUIPO (2016). European Union Intelectual Property. Annual Report 2015. European Union Intelectual Property Office, 2015. https://euipo.europa.eu/tunnel-web/secure/webdav/guest/document_library/contentPdfs/about _euipo/annual_report/annual_report_2015_en.pdf

Europeana 1914-1918. About. Europeana 1914-1918. http://www.europeana1914-1918.eu/en/about

FORWARD (2014). About FORWARD. http://project-forward.eu/forward-new/

Gramophon Online. What is this? Bringind the past to life. http://gramofononline.hu/en/whatisthis.php

Ministerio de Cultura (2002). Directrices para proyectos de digitalización de colecciones y fondos de dominio público, en particular de aquellos custodiados en bibliotecas y archivos. Madrid: Ministerio de Cultura. Secretaría General Técnica. Subdirección General de Publicaciones, Información y Documentación, 2002. // https://www.ifla.org/files/assets/preservation-and-conservation/publications/ digitization-projects-guidelines-es.pdf

National Library of Estonia (2017). DIGAR. Estonian articles. http://dea.digar.ee/cgi-bin/dea

National Széchényi Library (2015). ELDORADO. http://www.oszk.hu/en/eldorado/eldorado

Parlamento Europeo (2012). Directiva 2012/28/UE del Parlamento Europeo y del Consejo, de 25 de octubre de 2012, sobre ciertos usos autorizados de las obras huérfanas. Diario Oficial de la Unión Europea. 27 de Octubre de 2012. 299 (Serie L) 5-12.

Stratton, B (2011). Seeking new landscapes: a right clearance study in the context of mass digitization of 140 books published between 1870 and 2010. Londres: British Library, 2011. https://www.arrow-net.eu/sites/default/files/Seeking\%20New\%20Landscapes.pdf

TIB-AV Portal. About TIB-AV Portal. https://av.tib.eu/about

Vuopala, A (2010). Assessment of the Orphan works issue and Costs for Rights Clearance. Comisión Europea. DG Information Society and Media, 2010. http://www.acefilm.eu/wp-content/uploads/2010/09/Copyright anna report-1.pdf.

Enviado: 2017-04-07. Segunda versión: 2017-09-15. Aceptado: 2017-12-18. 
